\title{
Clinicopathological and immunohistochemical
} features of lung invasive mucinous adenocarcinoma
based on computed tomography findings

This article was published in the following Dove Press journal:

OncoTargets and Therapy

28 December 2016

Number of times this article has been viewed

\section{Katsuhiko Shimizu \\ Riki Okita \\ Shinsuke Saisho \\ Ai Maeda \\ Yuji Nojima \\ Masao Nakata}

Department of General Thoracic Surgery, Kawasaki Medical School, Kurashiki, Okayama, Japan
Correspondence: Katsuhiko Shimizu Department of General Thoracic Surgery, Kawasaki Medical School, 577 Matsushima, Kurashiki, Okayama 70I-0192, Japan

$\mathrm{Tel}+8 \mid 86464$ I। 24

Fax +8I 86464 II 24

Email kshimizu@med.kawasaki-m.ac.jp
Background: We performed an analysis to clarify differences in clinicopathological and molecular features of lung invasive mucinous adenocarcinoma (IMA) based on computed tomography (CT) findings and their impact on prognosis.

Patients and methods: On the basis of CT findings, we divided lung IMA into three subtypes: solid, bubbling, and pneumonic. We then investigated differences in clinicopathological characteristics, prognosis, and the expressions of well-identified biomarkers, including cyclooxygenase-2 (Cox-2), excision repair cross-complementation group 1 (ERCC1), ribonucleotide reductase M1 (RRM1), class III beta-tubulin, thymidylate synthase (TS), secreted protein acidic and rich in cysteine (SPARC), programmed cell death-1 ligand-1 (PD-L1), and epidermal growth factor receptor mutation, among the three subtypes.

Results: A total of 29 patients with resected lung IMA were analyzed. Compared with the solid or bubbling type, the pneumonic type had a higher proportion of symptoms, a larger tumor size, a higher pathological stage, and a significantly worse prognosis. The immunohistochemical findings tended to show high expression of RRM1, class III beta-tubulin, and Cox-2 in the tumor and of SPARC in the stroma, but not of ERCC1, TS, and PD-L1 in the tumor. None of the biomarkers with high expression levels in the tumor were prognostic biomarkers, but the expression of SPARC in the stroma was correlated with a poor outcome.

Conclusion: Clinical and pathological features, in conjunction with molecular data, indicate that IMA should be divided into different subgroups. In our results, the pneumonic type was correlated with a significantly worse outcome. Further studies should be performed to confirm our conclusion and to explore its molecular implications.

Keywords: non-small cell lung cancer, invasive mucinous adenocarcinoma, computed tomography finding, prognostic biomarker, secreted protein acidic and rich in cysteine, SPARC

\section{Introduction}

Lung cancer is a major cause of death in many developed countries. Surgical resection is the most important curative treatment option for this disease, especially early-stage non-small cell lung cancer (NSCLC). However, the 5-year survival rate of surgically treated NSCLC patients remains at $\sim 70 \%$. $^{1,2}$ Several biomarkers have now been reported as predictors of survival and recurrence in patients with NSCLC.

The most common pathological subtype of NSCLC is adenocarcinoma, the prevalence of which has been increasing. A new classification for lung adenocarcinoma was proposed by an international multidisciplinary expert panel of the International Association for the Study of Lung Cancer/American Thoracic Society/European Respiratory Society (IASLC/ATS/ERS) in $2011 .{ }^{3}$ Invasive mucinous adenocarcinoma (IMA) was 
recognized as a separate subtype of lung adenocarcinoma, whereas the definition of mucinous bronchioloalveolar carcinoma (BAC) is no longer used. IMA was supposed to contain components of columnar or goblet cells with abundant intracellular or extracellular mucus admixed with invasive adenocarcinoma patterns with stromal invasion. Compared with other lung adenocarcinoma subtypes, IMA has different immunohistochemical and molecular features. ${ }^{4-6}$ IMA also has a different progress pattern, compared with other subtypes of adenocarcinoma. In IMA, lymph node and distant metastasis are much less common than in other subtypes of adenocarcinoma. However, pulmonary metastasis frequently occurs in patients with IMA. ${ }^{7}$

Two recent studies have discussed subtypes of IMA according to computed tomography (CT) findings; reportedly, these subtypes are closely related to the clinical outcomes of IMA patients. ${ }^{8,9}$ However, sufficient evidence of optimal management based on IMA subtypes does not yet exist. Here, we report a retrospective study examining surgically resected lung IMA with the aim of clarifying differences in clinicopathological and immunohistochemical features among IMA subtypes based on CT findings. In addition, we examined the optimal management of IMA based on a biomarker analysis.

\section{Methods}

\section{Patients and specimens}

From October 2005 to September 2014, a total of 605 patients with primary lung cancer underwent surgical resection at our hospital. Of these 605 patients, 29 patients (4.8\%) presented with primary lung IMA. All the patients included in the present analysis met the following criteria: 1) curative resection and 2) neither radiotherapy nor chemotherapy administered prior to surgery. Written informed consent was obtained from each patient for the study of excised tissue samples from the surgical specimens. This study was conducted with the approval of the institutional Ethics Committee of Kawasaki Medical School (number 2159: approved on August 10, 2015).

\section{Evaluation of CT findings}

We classified the IMAs into three types based on the highresolution CT (HRCT) findings as follows: 1) solid type, in which the shadows represented solitary nodules or masses; 2) bubbling type, in which the shadows represented bubbling shadow; and 3 ) pneumonic type, in which the shadows represented consolidations with or without air bronchograms (Figure 1). ${ }^{8}$

\section{Immunohistochemical analysis}

Immunohistochemical analyses of resected, paraffin-embedded lung cancer tissues were performed. After microtome sectioning $(4 \mu \mathrm{m})$, the slides were processed for staining using an automated immunostainer (Nexes; Ventana, Tucson, AZ, USA). The streptavidin-biotin-peroxidase detection technique using diaminobenzidine as the chromogen was applied. The primary antibodies were used according to the manufacturer's instructions. The antibodies that were used are summarized in Table S1. ${ }^{10-15}$ The slides were examined by two investigators who had no knowledge of the corresponding clinicopathological data. The expression of each marker protein was examined and evaluated according to the original protocol, as reported previously.

Nuclear staining for thyroid transcription factor-1 (TTF-1) and excision repair cross-complementation group 1 (ERCC1) and cell membrane or cytoplasmic staining for cyclooxygenase-2 (Cox-2), cytokeratin 7 (CK7), CK20, ribonucleotide reductase M1 (RRM1), thymidylate synthase (TS), class III beta-tubulin, secreted protein acidic and rich in cysteine (SPARC), and programmed cell death-1 ligand-1 (PD-L1) were assessed (Figure S1).
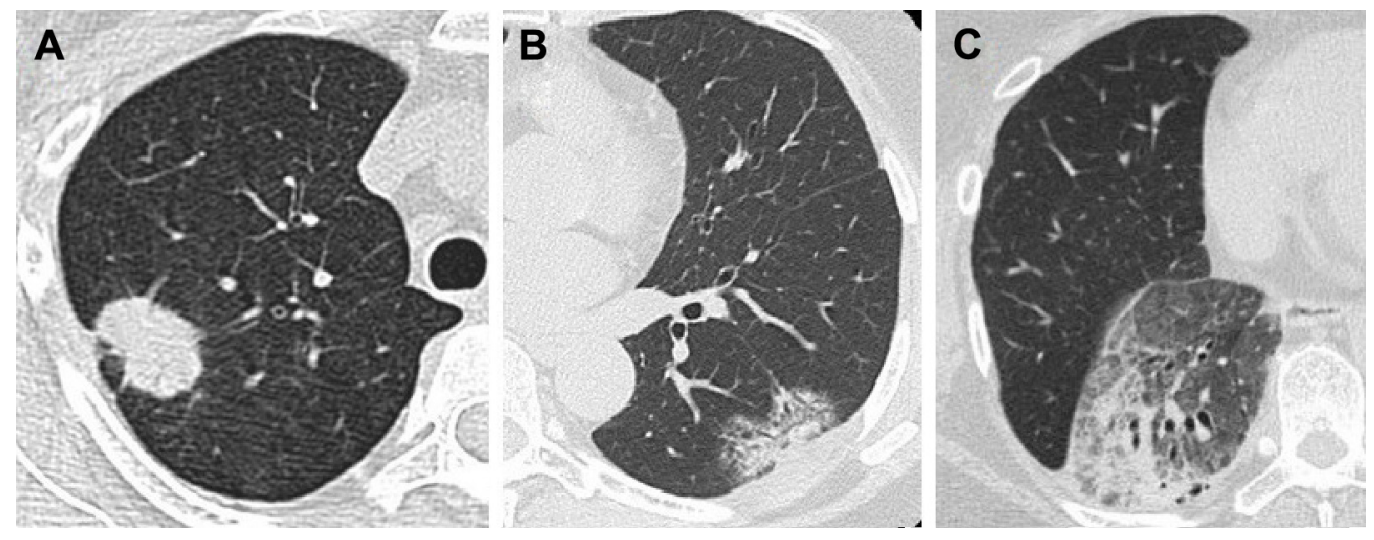

Figure I Computed tomography findings of lung invasive mucinous adenocarcinoma.

Notes: (A) Solid type, (B) bubbling type, and (C) pneumonic type. 
Immunoreactivity was evaluated semiquantitatively based on the intensity and estimated percentage of tumor cells that were stained. Intensity was quantified as follows: $1+$, weak staining (detection required high magnification); $2+$, moderate staining (readily detected at medium magnification); and 3+, strong staining (readily detected at low magnification). $H$ (histologic)-scores were derived by multiplying the percentage of immunoreactive cells $(0-100)$ by the intensity score $(0,1+, 2+$, and $3+)$, yielding a number between 0 and 300. SPARC staining was also evaluated using the $H$-score and was scored for two separate compartments: peritumoral stromal SPARC in fibroblasts and tumor epithelial SPARC. If the $H$-score exceeded the mean value, the test result was considered to be positive for that marker.

\section{EGFR mutation analysis}

An analysis to detect epidermal growth factor receptor (EGFR) mutations was performed using resected, paraffinembedded lung cancer tissues and the peptide nucleic acidlocked nucleic acid (PNA-LNA) polymerase chain reaction (PCR) clamp method. ${ }^{16}$ The PNA-LNA PCR clamp assay was performed at Mitsubishi Kagaku Bio-clinical Laboratories, Inc, Tokyo, Japan.

\section{Statistical analyses}

All the statistical analyses were performed using the SPSS statistical package (version 22.0; SPSS, Chicago, IL, USA). Categorical data were examined using the $\chi^{2}$ test. The prognostic evaluation was performed by considering the recurrence-free survival (RFS), which was defined as the time until lung cancer recurrence or nonlung cancerrelated death. The survival curves were estimated using the Kaplan-Meier method. Two-sided $P$-values of $<0.05$ were considered statistically significant.

\section{Results \\ Relationship between the clinical and HRCT findings of IMA}

Table 1 shows the clinical characteristics of the patients according to the IMA subtypes based on HRCT findings. Among the clinical findings, the pneumonic type was associated with a higher proportion of symptoms $(P=0.004)$ and a large tumor size $(P=0.001)$. The bubbling type was associated with a lower maximal standardized uptake value (SUVmax) on fluorodeoxyglucose-positron emission tomography $(P=0.002)$.

\section{Relationship between pathological and HRCT findings of IMA}

Among the pathological findings, no statistically significant associations were observed between lymph node metastasis, lymphatic invasion, vascular invasion, or pleural involvement and the HRCT findings among the subtypes (Table 2). However, the pneumonic type was associated with a higher pathological stage because of its relatively large tumor size $(P=0.017)$. As many previous reports have indicated, the expression of TTF-1 was low and the expressions of CK7 and 20 were high for all subtypes. ${ }^{11}$ EGFR mutation was positive in only $13.8 \%(4 / 29)$ cases.

\section{Surgical procedure and prognosis}

All patients with pneumonic type received standard lobectomy. Five patients with solid or bubbling type received wedge resection, who were considered at increased risk for standard resection because of poor physiologic respiratory reserve. Nine patients received adjuvant chemotherapy, who were pathologically diagnosed with large tumor size $(>4 \mathrm{~cm})$ or lymph node metastasis.

Table I Clinical characteristics of patients based on computed tomography findings

\begin{tabular}{lllll}
\hline Characteristics & Solid type & Bubbling type & Pneumonic type & P-value \\
\hline Patients & 10 & 9 & 10 & $73.6 \pm 4.7$ \\
Age (years) & $70.9 \pm 12.4$ & $71.3 \pm 7.7$ & 6 & 0.458 \\
Sex & 6 & 5 & 4 & 0.975 \\
Male & 4 & 4 & 6 & \\
Female & & & 4 & \\
Smoking history & 4 & 5 & 6 & \\
Negative & 6 & 4 & 4 & 0.645 \\
Positive & 1 & & $65.0 \pm 29.9$ \\
Symptom & 9 & 0 & $6.1 \pm 2.3(9 / 10)$ & 0.004 \\
Negative & $23.6 \pm 7.2$ & 9 & $22.2 \pm 10.8$ & 0.002 \\
Positive & $4.7 \pm 4.3(8 / 10)$ & $1.6 \pm 1.2(7 / 9)$ & \\
Tumor size $(\mathrm{mm})$ & &
\end{tabular}

Note: Data presented as $n$, mean $\pm S D$, or $(n / N)$.

Abbreviation: SUVmax, maximal standardized uptake value. 
Table 2 Pathological characteristics of patients based on computed tomography findings

\begin{tabular}{|c|c|c|c|c|}
\hline Characteristics & Solid type & Bubbling type & Pneumonic type & $P$-value \\
\hline Patients & 10 & 9 & 10 & \\
\hline Tumor size $(\mathrm{mm})$ & $21.8 \pm 6.5$ & $23.8 \pm 11.4$ & $59.7 \pm 17.8$ & 0.001 \\
\hline Lymph node metastasis & & & & 0.996 \\
\hline Negative & 9 & 8 & 9 & \\
\hline Positive & 1 & I & I & \\
\hline Lymphatic invasion & & & & 0.352 \\
\hline Negative & 8 & 9 & 8 & \\
\hline Positive & 2 & 0 & 2 & \\
\hline Vascular invasion & & & & 0.617 \\
\hline Negative & 9 & 9 & 9 & \\
\hline Positive & 1 & 0 & I & \\
\hline Pleural involvement & & & & 0.152 \\
\hline Negative & 7 & 9 & 9 & \\
\hline Positive & 3 & 0 & I & \\
\hline Pathological stage & & & & 0.017 \\
\hline $\mathrm{IA} / \mathrm{IB}$ & $5 / 4$ & $7 / 1$ & $0 / 3$ & \\
\hline IIA/IIB & $0 / 0$ & $\mathrm{I} / 0$ & $3 / 3$ & \\
\hline IIIA & 1 & 0 & 1 & \\
\hline TTF-I expression & & & & 0.283 \\
\hline Negative & 9 & 7 & 10 & \\
\hline Positive & 1 & 2 & 0 & \\
\hline CK7 expression & & & & 0.316 \\
\hline Negative & 0 & 1 & 0 & \\
\hline Positive & 10 & 8 & 10 & \\
\hline CK20 expression & & & & $0.86 I$ \\
\hline Negative & 3 & 2 & 2 & \\
\hline Positive & 7 & 7 & 8 & \\
\hline EGFR mutation & & & & 0.677 \\
\hline Negative & 9 & 7 & 9 & \\
\hline Positive & 1 & 2 & I & \\
\hline
\end{tabular}

Note: Data presented as $n$, mean $\pm S D$, or $(n / N)$.

Abbreviations: CK, cytokeratin; EGFR, epidermal growth factor receptor; TTF-I, thyroid transcription factor-I.

Seven (24.1\%) patients developed cancer recurrence after resection. A significant association between pneumonic-type IMA and a high rate of recurrence $(60.0 \%$ vs $10.0 \%$ for solid type and $0 \%$ for bubbling type, $P=0.004$ ) was observed. The initial recurrence sites are shown in Table 3. All the initial recurrences were intrathoracic metastases, such as lung metastasis, pleural dissemination, and mediastinal lymph node metastasis. No cases of extrathoracic metastasis of IMA occurred in this series.

The median follow-up time was 980 days. The 5-year RFS rate was $87.5 \%$ for solid type, $88.9 \%$ for bubbling type, and $25.0 \%$ for pneumonic type. Compared with the solid or bubbling types, the pneumonic type had a significantly poorer RFS $(P=0.018)$ (Figure 2).

Table 3 Prognosis of patients based on computed tomography findings

\begin{tabular}{|c|c|c|c|c|}
\hline Characteristics & Solid type (n) & Bubbling type (n) & Pneumonic type (n) & $P$-value \\
\hline Patients & 10 & 9 & 10 & \\
\hline Recurrence & & & & 0.004 \\
\hline Intrathoracic & $\mathrm{I}^{\mathrm{a}}$ & 0 & 6 & \\
\hline Extrathoracic & 0 & 0 & 0 & \\
\hline \multicolumn{5}{|c|}{ Intrathoracic recurrence } \\
\hline Lung & 0 & 0 & 6 & \\
\hline Dissemination & $\mathrm{I}^{\mathrm{a}}$ & 0 & $\mathrm{I}^{\mathrm{b}}$ & \\
\hline Lymph node & 0 & 0 & $I^{c}$ & \\
\hline \multicolumn{5}{|l|}{ Death } \\
\hline Lung cancer & 1 & 0 & 2 & \\
\hline Other cancer & 0 & I & 0 & \\
\hline Noncancer & 0 & 0 & 0 & \\
\hline
\end{tabular}

Notes: ${ }^{a}$ Case of wedge resection due to compromised patient. 'bung + pleural dissemination $(n=I)$. 'Lung + mediastinal lymph node metastasis $(n=I)$. 


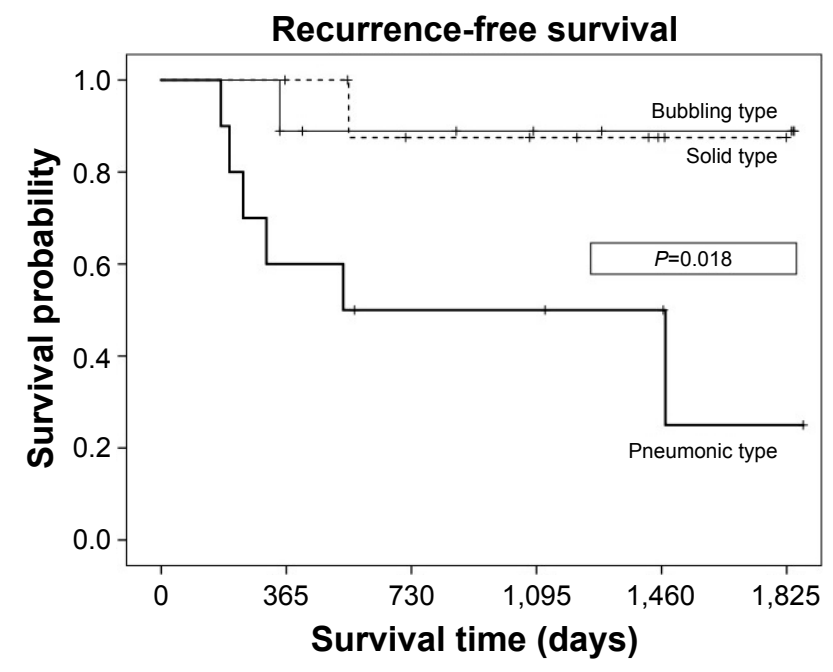

Figure 2 Kaplan-Meier recurrence-free survival curve based on computed tomography findings.

\section{Biomarker analysis}

For the immunohistochemical analysis, the $H$-score for each marker expression profile was shown according to the subtypes based on the CT findings (Figure 3). In an overall analysis, the $H$-score of the markers were as follows: ERCC1, 66.2 \pm 67.6 ; RRM1, 178.8 \pm 81.5 ; class III betatubulin, 103.1 \pm 71.7 ; TS, $2.4 \pm 6.4$; SPARC in tumor tissues, 32.4 \pm 34.6 ; SPARC in stroma, 126.0 \pm 65.2 ; PD-L1, 2.0 \pm 3.5 ; and Cox-2, 170.5 \pm 68.6 . The expressions of RRM1, class III beta-tubulin, Cox-2 in tumor, and SPARC in stroma were relatively high in all the IMA subtypes, whereas those of ERCC1, TS, and PD-L1 were relatively low. Of these, only the $H$-score of SPARC in stroma was significantly higher in the pneumonic type than in the solid $(P=0.029)$ or bubbling type $(P=0.048)$.

As to the RFS, none of the biomarkers were prognostic factors. However, the RFS of patients with positive SPARC expression in stroma tissue was significantly poorer than that of patients with negative SPARC expression in stroma tissue $(P=0.028$; Figure 4).

\section{Discussion}

We undertook this study to investigate whether it is reasonable to divide IMA into separate subtypes. To our knowledge, this is the first study to focus on the differences in prognosis and molecular alterations in IMA subgroups with different morphological features. Since the appearance of the IASLC/ ATS/ERS classification for lung adenocarcinoma in 2011, many studies have focused on the influence of the pathological subtype on prognosis and molecular changes. ${ }^{17-19}$ IMAs, which account for $2 \%-10 \%$ of lung adenocarcinoma cases in East Asia, Europe, and the US, were considered to be more malignant than other common subtypes of lung adenocarcinoma, such as lepidic and acinar subtypes. ${ }^{19-22}$ Nonmucinous adenocarcinomas originate from type-II pneumocystis or Clara cells, whereas IMAs most likely originate from bronchiolar lining cells that have undergone mucinous (goblet cell) metaplasia. IMAs show a strong tendency for multicentric, multilobar, and bilateral lung involvement, which may reflect aerogenous spread. ${ }^{11}$ IMA is also strongly correlated (76\%) with KRAS mutation and almost entirely lacks $E G F R$ mutations, whereas nonmucinous adenocarcinoma in situ/minimally invasive adenocarcinoma/lepidic predominant adenocarcinoma exhibit the opposite trends with $45 \%$ of cases positive for $E G F R$ mutation but only $13 \%$ positive for KRAS mutation. ${ }^{23}$

Generally, mucinous adenocarcinomas in other organs are also associated with lymph node metastasis and a poor prognosis. ${ }^{24-26}$ The reason is that the mucus is considered to play a critical role in the development of cancer. ${ }^{27}$ In this study, the prognosis of resected IMA of the lung was relatively good, because lung IMA was not associated with lymph node metastasis. However, patients with pneumonic type had a poorer prognosis than those with other types. This subtype was also observed to have a higher rate of intrathoracic metastasis and was associated with a poor prognosis.

Recently, both experimental and clinical studies have revealed that many molecules contribute to various biological behaviors of malignant tumors, including NSCLC. New strategies based on a better understanding of tumor biology are, thus, needed to maximize the efficacy of current treatments. The associations between these strategies and the response to chemotherapy have been investigated, and the selection of effective chemotherapy regimens based on the evaluation of these biomarkers may improve the clinical outcome of NSCLC patients. Platinum-based chemotherapy remains the scaffold upon which combination chemotherapy regimens are assembled for NSCLC patients. As a predictor of the efficacy of platinum-based chemotherapy, the intratumoral expression of ERCC1, a major component of the nucleotide excision repair pathway, is reported to be associated with a lower responsiveness of patients to cisplatin. ${ }^{28,29}$ In addition, the intratumoral expression of class III beta-tubulin is likely to be associated with a lower responsiveness to taxanes, such as paclitaxel and docetaxel. ${ }^{30,31}$ Moreover, RRM1 is likely to be associated with a lower responsiveness to gemcitabine. ${ }^{32}$ The expression of TS protein was associated with a reduced sensitivity of patients to pemetrexed treatment. ${ }^{33,34}$ Our results showed that the expressions of RRM1 and class III beta-tubulin were relatively high, whereas those of ERCC1 and TS were relatively low in IMA. Thus, we suspect that 
IMA might be susceptible to cisplatin or pemetrexed, but not to gemcitabine or taxans.

SPARC plays remarkable roles in altering the activity and the microenvironment of cancer cells, modulating cell growth, apoptosis, adhesion, migration, and invasion in human carcinogenesis. ${ }^{35,36}$ Thus, many studies have evaluated the effect of SPARC expression in many cancers. SPARC has generated remarkable interest as a potential molecular

\section{ERCC1}

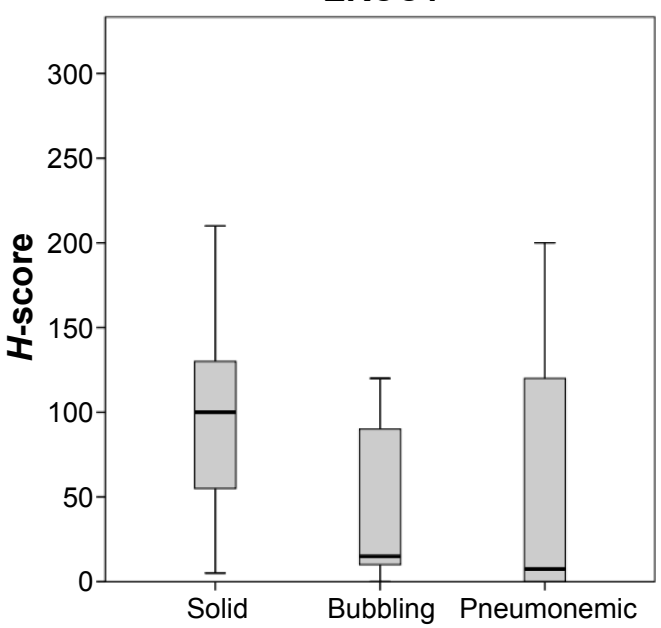

\begin{tabular}{|l|l|l|l|}
\hline \multicolumn{4}{|c|}{ H-score } \\
\hline Median & 93 & 15 & 8 \\
\hline Range & $5-210$ & $0-120$ & $0-200$ \\
\hline Mean & 97 & 48 & 52 \\
\hline SD & 70 & 49 & 75 \\
\hline
\end{tabular}

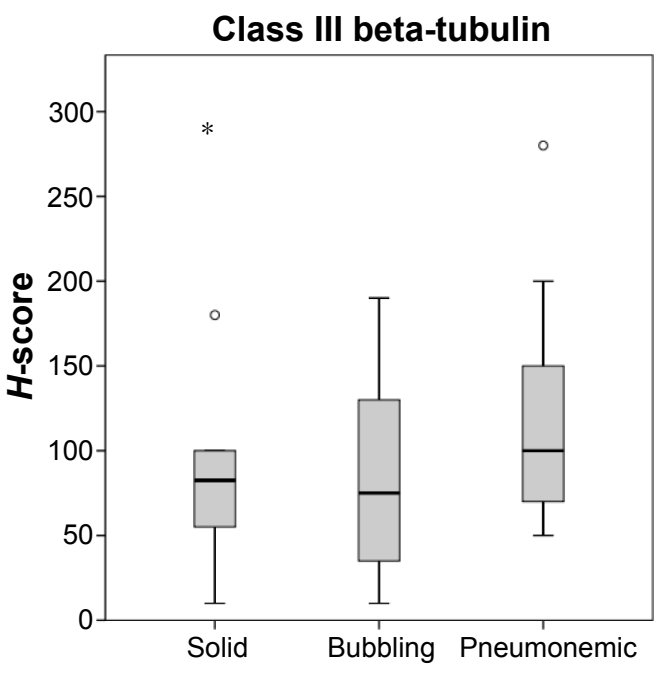

\begin{tabular}{|l|l|l|l|}
\hline \multicolumn{4}{|c|}{ H-score } \\
\hline Median & 85 & 73 & 100 \\
\hline Range & $10-290$ & $10-190$ & $50-280$ \\
\hline Mean & 101 & 85 & 121 \\
\hline SD & 80 & 65 & 72 \\
\hline
\end{tabular}

marker of prognosis for malignant tumors. However, whether a high or low, SPARC expression level is correlated with a poor survival outcome remains controversial. In pancreatic cancer, Han et al reported that high SPARC expression in the stroma, but not in the tumor, was a strong predictor of a shorter survival period. ${ }^{37}$ Compared with its expression in tumor cells, the overexpression of SPARC is frequently found in the stroma in pancreatic cancer. ${ }^{38}$ In the present
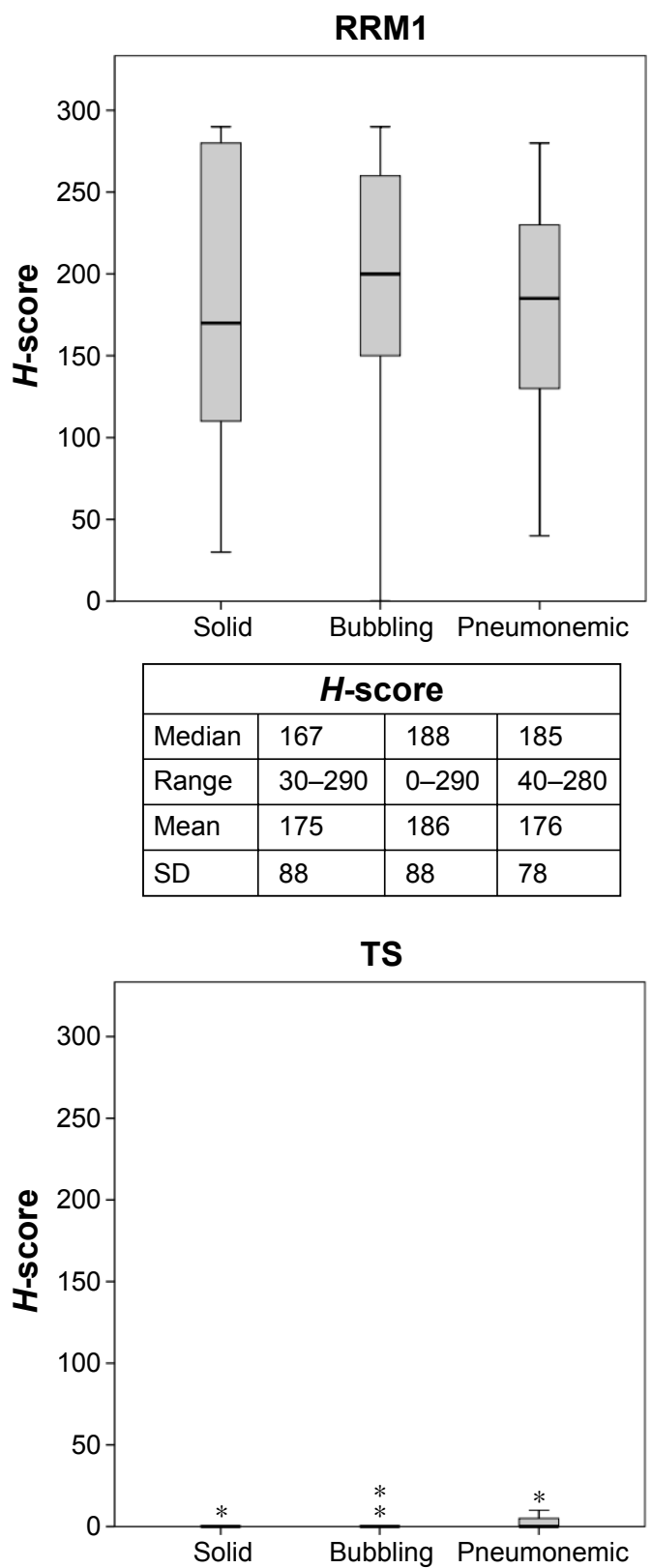

\begin{tabular}{|l|l|l|l|}
\hline \multicolumn{4}{|c|}{ H-score } \\
\hline Median & 0.5 & 1.3 & 1.9 \\
\hline Range & $0-5$ & $0-15$ & $0-30$ \\
\hline Mean & 0.5 & 2.2 & 4.5 \\
\hline SD & 1.6 & 5.1 & 9.6 \\
\hline
\end{tabular}



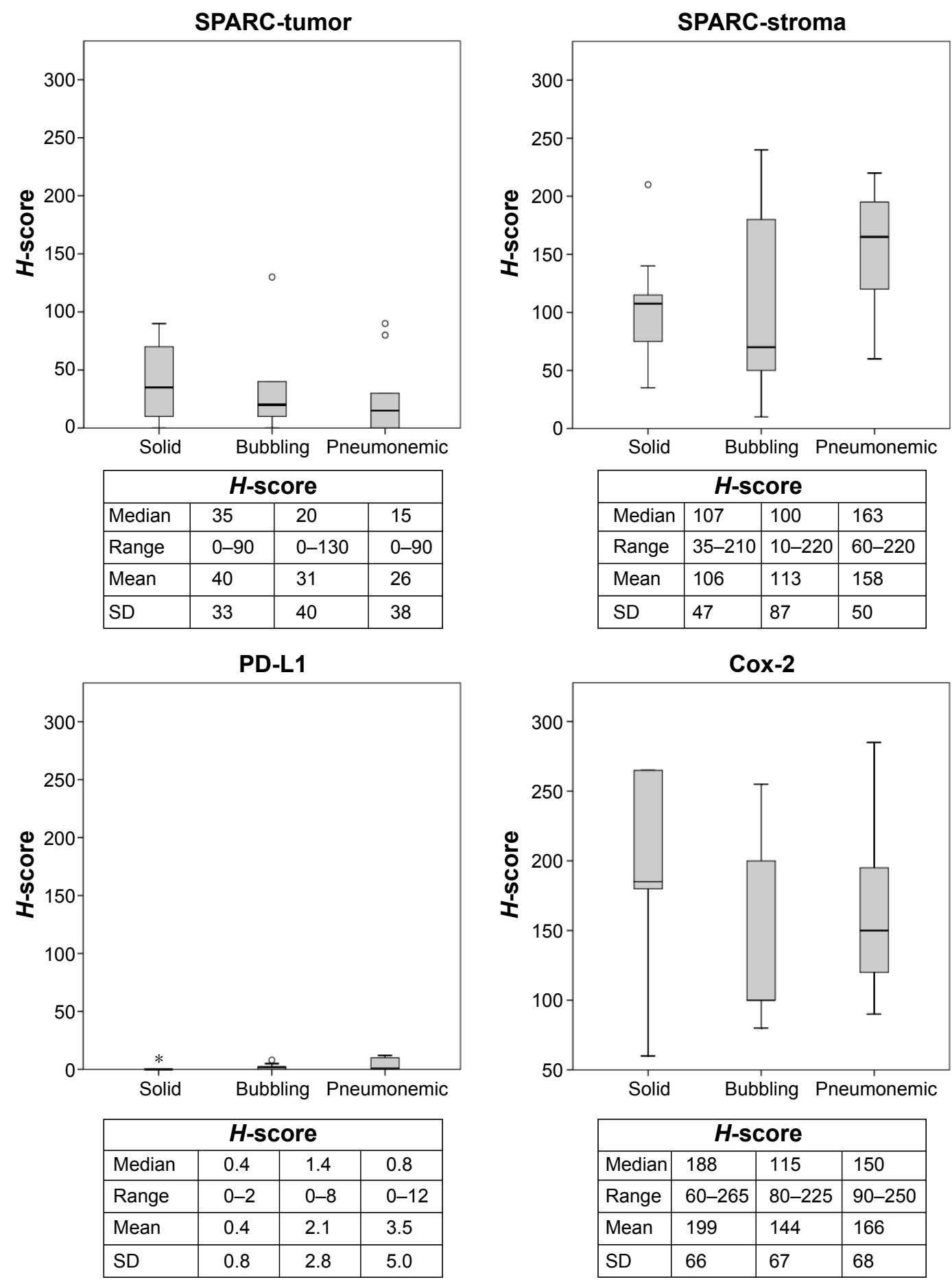

Figure 3 The immunohistochemical $H$-score for each marker expression profile based on the computed tomography findings.

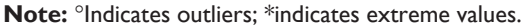

Abbreviations: Cox-2, cyclooxygenase-2; ERCCI, excision repair cross-complementation group I; H-score, histologic score; PD-LI, programmed cell death-I ligand-I; RRMI, ribonucleotide reductase MI; SD, standard deviation; SPARC, secreted protein acidic and rich in cysteine; TS, thymidylate synthase.

results, the level of SPARC expression in the stroma was relatively high and seemed to be similar to that in pancreatic cancer. SPARC was considered to be a predictive biomarker of response to nab-paclitaxel in three different clinical trials for melanoma, pancreatic, and breast cancer..$^{39}$ Our present results showing a high level of SPARC expression in the stroma suggest that IMA, especially pneumonic type, might be susceptible to nab-paclitaxel.

In 2015, nivolumab, a new immunotherapy drug, was approved by the Food and Drug Administration for the treatment of lung cancer after the termination of standard chemotherapy. ${ }^{15,40}$ Especially in nonsquamous NSCLC, nivolumab was associated 
A

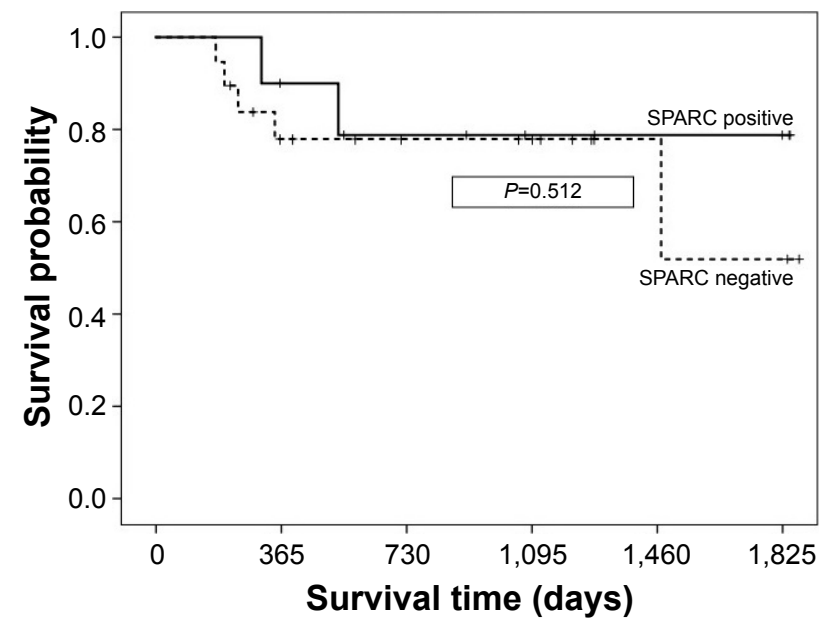

B

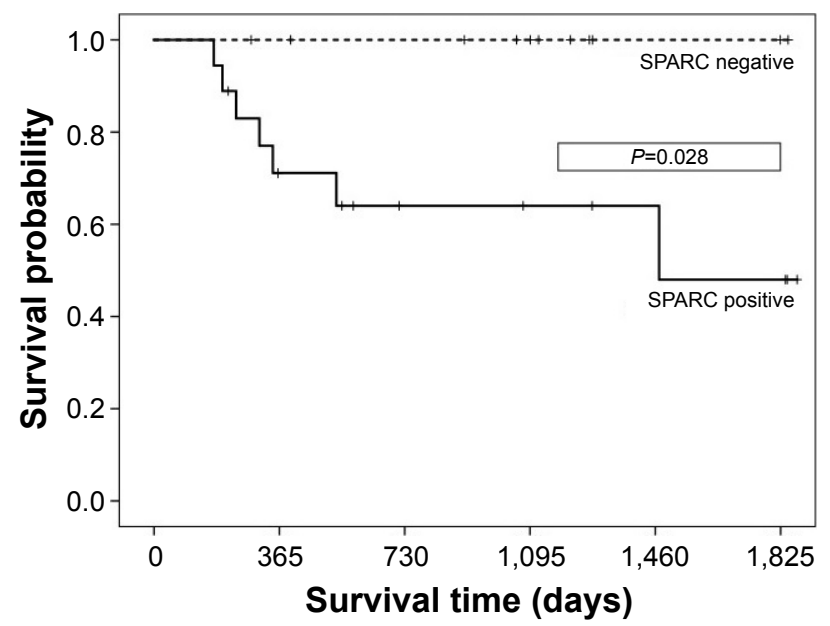

Figure 4 Kaplan-Meier recurrence-free survival curve according to SPARC expression. Notes: (A) Tumor tissue. (B) Stroma tissue.

Abbreviation: SPARC, secreted protein acidic and rich in cysteine.

with greater efficacy in subgroups defined according to prespecified levels of PD-L1. However, our results suggested that IMA might not be susceptible to nivolumab because the IMA specimens had low PD-L1 expression levels. ${ }^{15}$

In this study, the $H$-score for Cox-2 tended to be high in tumor cells. In 2008, Edelman et al reported that Cox-2 expression was a significant prognostic factor in patients with advanced NSCLC (Cancer and Leukemia Group B Trial 30203). Moreover, patients with moderate to high levels of Cox-2 expression had a better tumor response to a Cox-2 inhibitor (celecoxib) in terms of a longer median survival period compared with those not receiving celecoxib. ${ }^{10}$

\section{Limitations}

The present study had several limitations. The clinical outcomes were of limited significance because some of the patients had different postoperative treatments. Meanwhile, a sample size of 29 patients is too small to confirm differences among IMA subgroups with different morphological features. The present findings need to be validated by further research with larger samples.

\section{Conclusion}

We found three subtypes of lung IMAs based on CT findings. This study represents the first comparison of clinical features and biomarker expressions in IMAs. Clinical and pathological features in conjunction with molecular data indicate that IMA should be divided into different subgroups. Further studies should be performed to confirm our conclusions and to explore the underlying molecular functions.

\section{Acknowledgments}

This work was supported, in part, by a Research Project Grant (number 26-64) from Kawasaki Medical School. The authors thank Kiyomi Maitani for providing technical assistance and IMIC for the English language review.

\section{Disclosure}

The authors report no conflicts of interest in this work.

\section{References}

1. Asamura H, Goya T, Koshiishi Y, et al. A Japanese lung cancer registry study: prognosis of 13,010 resected lung cancers. J Thorac Oncol. 2008;3(1):46-52.

2. Sawabata N, Miyaoka E, Asamura H, et al. Japanese lung cancer registry study of 11,663 surgical cases in 2004: demographic and prognosis changes over decade. J Thorac Oncol. 2011;6(7):1229-1235.

3. Travis WD, Brambilla E, Noguchi M, et al. International Association for the Study of Lung Cancer/American Thoracic Society/European Respiratory Society international multidisciplinary classification of lung adenocarcinoma. J Thorac Oncol. 2011;6(2):244-285.

4. Zhang Y, Sun Y, Xiang J, Zhang Y, Hu H, Chen H. A clinicopathologic prediction model for postoperative recurrence in stage Ia non-small cell lung cancer. J Thorac Cardiovasc Surg. 2014;148(4):1193-1199.

5. Casali C, Rossi G, Marchioni A, et al. A single institution-based retrospective study of surgically treated bronchioloalveolar adenocarcinoma of the lung: clinicopathologic analysis, molecular features, and possible pitfalls in routine practice. $J$ Thorac Oncol. 2010;5(6):830-836.

6. Goldstein NS, Thomas M. Mucinous and nonmucinous bronchioloalveolar adenocarcinomas have distinct staining patterns with thyroid transcription factor and cytokeratin 20 antibodies. Am J Clin Pathol. 2001;116(3):319-325.

7. Wislez M, Antoine M, Baudrin L, et al. Non-mucinous and mucinous subtypes of adenocarcinoma with bronchioloalveolar carcinoma features differ by biomarker expression and in the response to gefitinib. Lung Cancer. 2010;68(2):185-191.

8. Watanabe H, Saito H, Yokose T, et al. Relation between thin-section computed tomography and clinical findings of mucinous adenocarcinoma. Ann Thorac Surg. 2015;99(3):975-981. 
9. Lee HY, Lee KS, Han J, et al. Mucinous versus nonmucinous solitary pulmonary nodular bronchioloalveolar carcinoma: CT and FDG PET findings and pathologic comparisons. Lung Cancer. 2009;65(2):170-175.

10. Edelman MJ, Watson D, Wang X, et al. Eicosanoid modulation in advanced lung cancer: cyclooxygenase- 2 expression is a positive predictive factor for celecoxib + chemotherapy-Cancer and Leukemia Group B Trial 30203. J Clin Oncol. 2008;26(6):848-855.

11. Simsir A, Wei XJ, Yee H, Moreira A, Cangiarella J. Differential expression of cytokeratins 7 and 20 and thyroid transcription factor-1 in bronchioloalveolar carcinoma: an immunohistochemical study in fine-needle aspiration biopsy specimens. Am J Clin Pathol. 2004; 121(3):350-357.

12. He YW, Zhao ML, Yang XY, Zeng J, Deng QH, He JX. Prognostic value of ERCC1, RRM1, and TS proteins in patients with resected non-small cell lung cancer. Cancer Chemother Pharmacol. 2015; 75(4):861-867.

13. Sève $\mathrm{P}$, Lai R, Ding $\mathrm{K}$, et al. Class III beta-tubulin expression and benefit from adjuvant cisplatin/vinorelbine chemotherapy in operable non-small cell lung cancer: analysis of NCIC JBR.10. Clin Cancer Res. 2007;13(3):994-999.

14. Hidalgo M, Plaza C, Musteanu M, et al. SPARC Expression Did Not Predict Efficacy of nab-Paclitaxel plus Gemcitabine or Gemcitabine Alone for Metastatic Pancreatic Cancer in an Exploratory Analysis of the Phase III MPACT Trial. Clin Cancer Res. 2015;21(21):4811-4818.

15. Borghaei H, Paz-Ares L, Horn L, et al. Nivolumab versus docetaxel in advanced nonsquamous non-small-cell lung cancer. $N$ Engl J Med. 2015;373(17):1627-1639.

16. Nagai Y, Miyazawa H, Huqun, et al. Genetic heterogeneity of the epidermal growth factor receptor in non-small cell lung cancer cell lines revealed by a rapid and sensitive detection system, the peptide nucleic acid-locked nucleic acid PCR clamp. Cancer Res. 2005;65(16):7276-7282.

17. Hung JJ, Jeng WJ, Chou TY, et al. Prognostic value of the new international association for the study of lung cancer/American thoracic society/European respiratory society lung adenocarcinoma classification on death and recurrence in completely resected stage I lung adenocarcinoma. Ann Surg. 2013;258(6):1079-1086.

18. Russell PA, Barnett SA, Walkiewicz M, et al. Correlation of mutation status and survival with predominant histologic subtype according to the new IASLC/ATS/ERS lung adenocarcinoma classification in stage III (N2) patients. J Thorac Oncol. 2013;8(4):461-468.

19. Warth A, Muley T, Meister M, et al. The novel histologic International Association for the Study of Lung Cancer/American Thoracic Society/ European respiratory society classification system of lung adenocarcinoma is a stage-independent predictor of survival. J Clin Oncol. 2012; 30(13):1438-1446.

20. Tsuta K, Kawago M, Inoue E, et al. The utility of the proposed IASLC/ ATS/ERS lung adenocarcinoma subtypes for disease prognosis and correlation of driver gene alterations. Lung Cancer. 2013;81(3): 371-376

21. Yoshizawa A, Motoi N, Riely GJ, et al. Impact of proposed IASLC/ ATS/ERS classification of lung adenocarcinoma: prognostic subgroups and implications for further revision of staging based on analysis of 514 stage I cases. Mod Pathol. 2011;24(5):653-664.

22. Cadranel J, Quoix E, Baudrin L, et al. IFCT-0401 Trial Group IFCT0401 Trial: a phase II study of gefitinib administered as first-line treatment in advanced adenocarcinoma with bronchioloalveolar carcinoma subtype. J Thorac Oncol. 2009;4(9):1126-1135.

23. Tang ER, Schreiner AM, Pua BB. Advances in lung adenocarcinoma classification: a summary of the new international multidisciplinary classification system (IASLC/ATS/ERS). J Thorac Dis. 2014;6(Suppl 5): S489-S501.
24. Consorti F, Lorenzotti A, Midiri G, Di Paola M. Prognostic significance of mucinous carcinoma of colon and rectum: a prospective case-control study. J Surg Oncol. 2000;73(2):70-74.

25. Enciu M, Aşchie M, Deacu M, Poinăreanu I. Morphological characteristics of a mucinous adenocarcinoma of the prostate: differential diagnosis considerations. Rom J Morphol Embryol. 2013;54(1):191-194.

26. Kunisaki C, Akiyama H, Nomura M, et al. Clinicopathologic characteristics and surgical outcomes of mucinous gastric carcinoma. Ann Surg Oncol. 2006;13(6):836-842.

27. Beatty PL, Narayanan S, Gariépy J, Ranganathan S, Finn OJ. Vaccine against MUC1 antigen expressed in inflammatory bowel disease and cancer lessens colonic inflammation and prevents progression to colitis-associated colon cancer. Cancer Prev Res (Phila). 2010; 3(4):438-446.

28. Lord RV, Brabender J, Gandara D, et al. Low ERCC1 expression correlates with prolonged survival after cisplatin plus gemcitabine chemotherapy in non-small cell lung cancer. Clin Cancer Res. 2002;8(7): 2286-2291.

29. Olaussen KA, Dunant A, Fouret P, et al. DNA repair by ERCC1 in non-small cell lung cancer and cisplatin-based adjuvant chemotherapy. N Engl J Med. 2006;355(10):983-991.

30. Seve P, Mackey J, Isaac S, et al. Class III $\beta$-tubulin expression in tumor cells predicts response and outcome in patients with non-small cell lung cancer receiving paclitaxel. Mol Cancer Ther. 2005;4(12): 2001-2007.

31. Reiman T, Lai R, Veillard AS, et al. Cross-validation study of class III beta-tubulin as a predictive marker for benefit from adjuvant chemotherapy in resected non-small-cell lung cancer: analysis of four randomized trials. Ann Oncol. 2012;23(1):86-93.

32. Bepler G, Williams C, Schell MJ, et al. Randomized international phase III trial of ERCC1 and RRM1 expression-based chemotherapy versus gemcitabine/carboplatin in advanced non-small-cell lung cancer. J Clin Oncol. 2013;31(19):2404-2412.

33. Nicolson MC, Fennell DA, Ferry D, et al. Thymidylate synthase expression and outcome of patients receiving pemetrexed for advanced nonsquamous non-small-cell lung cancer in a prospective blinded assessment phase II clinical trial. J Thorac Oncol. 2013;8(7):930-939.

34. Shimizu T, Nakanishi Y, Nakagawa Y, et al. Association between expression of thymidylate synthase, dihydrofolate reductase, and glycinamide ribonucleotide formyltransferase and efficacy of pemetrexed in advanced non-small cell lung cancer. Anticancer Res. 2012;32(10): 4589-4596.

35. Bradshaw AD. Diverse biological functions of the SPARC family of proteins. Int J Biochem Cell Biol. 2012;44(3):480-488.

36. Nagaraju GP, Dontula R, El-Rayes BF, Lakka SS. Molecular mechanisms underlying the divergent roles of SPARC in human carcinogenesis. Carcinogenesis. 2014;35(5):967-973.

37. Han W, Cao F, Chen MB, et al. Prognostic value of SPARC in patients with pancreatic cancer: a systematic review and meta-analysis. PLoS One. 2016;11:e0145803.

38. Sato N, Fukushima N, Maehara N, et al. SPARC/osteonectin is a frequent target for aberrant methylation in pancreatic adenocarcinoma and a mediator of tumor-stromal interactions. Oncogene. 2003;22: 5021-5030.

39. Desai N, Trieu V, Knauer D, et al. SPARC may be a predictive biomarker of response to nab-paclitaxel. Eur J Cancer. 2009;7(23):88.

40. Brahmer J, Reckamp KL, Baas P, et al. Nivolumab versus docetaxel in advanced squamous-cell non-small-cell lung cancer. $N$ Engl J Med. 2015;373(2):123-135 


\section{Supplementary materials}

Table SI Antibodies and conditions

\begin{tabular}{|c|c|c|c|c|c|}
\hline Antibody & Clone & Duration & Localization & Source & References \\
\hline Cox-2 & CX-294 & $\mathrm{I}: 50$ & Cytoplasm & DAKO, Carpinteria, CA, USA & Edelman et al' \\
\hline TTF-I & $8 G 7 G 3 / 1$ & $\mathrm{I}: 50$ & Nuclei & Abcam, Cambridge, MA, USA & Simsir et $\mathrm{al}^{2}$ \\
\hline CK7 & SP52 & $\mathrm{I}: 100$ & Cytoplasm & Abcam & Simsir et $\mathrm{al}^{2}$ \\
\hline CK20 & EPRI622Y & $\mathrm{I}: 100$ & Cytoplasm & Abcam & Simsir et $\mathrm{al}^{2}$ \\
\hline $\mathrm{ERCCI}$ & $8 \mathrm{FI}$ & $\mathrm{I}: 100$ & Nuclei & Abcam & $\mathrm{He}$ et $\mathrm{al}^{3}$ \\
\hline RRMI & Polyclonal & $\mathrm{I}: 50$ & Cytoplasm & Abcam & He et $\mathrm{al}^{3}$ \\
\hline TS & ATYMSMAB & $\mathrm{I}: 500$ & Cytoplasm & $\begin{array}{l}\text { Immuno-Biological Laboratories Co., Ltd., } \\
\text { Fujioka-Shi, Japan }\end{array}$ & He et $\mathrm{al}^{3}$ \\
\hline Class III beta-tubulin & TUJI & $\mathrm{I}: 400$ & Cytoplasm & BioLegend, San Diego, CA, USA & Sève et $\mathrm{al}^{4}$ \\
\hline SPARC & Polyclonal & $\mathrm{I}: 500$ & Cytoplasm & Atlas Antibodies AB, Bromma, Sweden & Hidalgo et $\mathrm{a}^{5}$ \\
\hline PD-LI & SPI42 & $\mathrm{I}: 100$ & Cell membrane & Spring Bioscience, Pleasanton, CA, USA & Borghaei et al \\
\hline
\end{tabular}

Abbreviations: CK, cytokeratin; Cox-2, cyclooxygenase-2; ERCCI, excision repair cross-complementation group I; PD-LI, programmed cell death-I ligand-I; RRMI, ribonucleotide reductase MI; SPARC, secreted protein acidic and rich in cysteine; TS, thymidylate synthase; TTF-I, thyroid transcription factor-I.
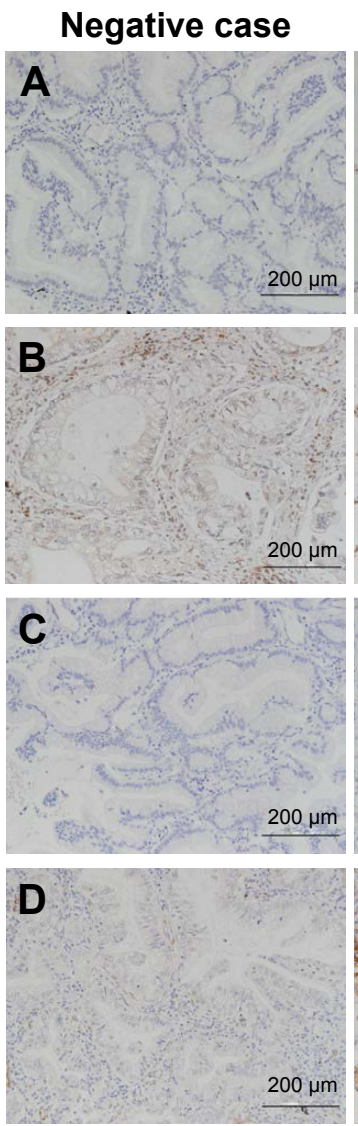

Positive case
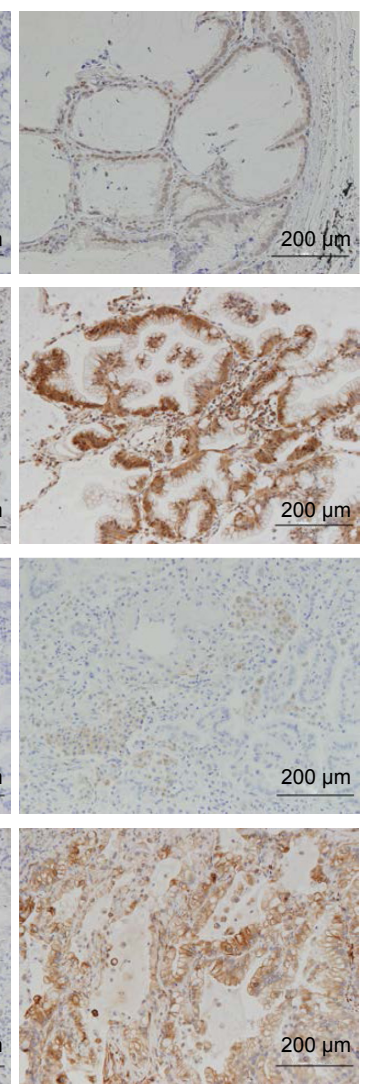

Negative case
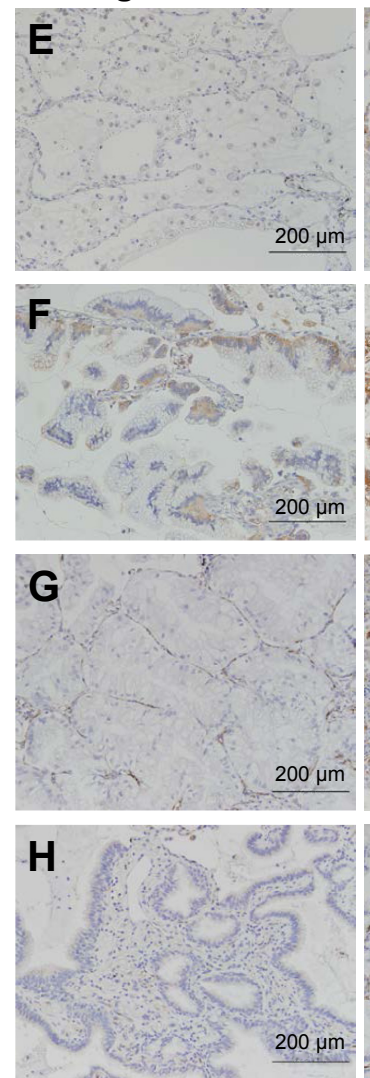

Positive case
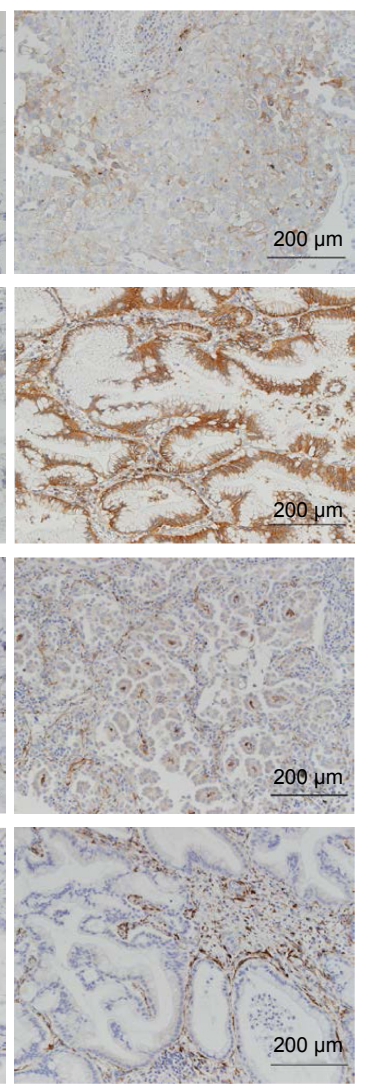

Figure SI Representative photomicrographs of biomarker expression.

Notes: Magnification $\times 200$. (A) ERCCI; nuclear staining, mean $H$-score: 66, negative case score: 0 , positive case score: 190. (B) RRMI; cytoplasmic staining, mean $H$-score: 178, negative case score: 0 , positive case score: 260 . (C) TS; cytoplasmic staining, mean $H$-score: 2.4 , negative case score: 0 , positive case score: 30 . (D) Class III beta-tubulin, cytoplasmic staining, mean $\mathrm{H}$-score: 126, negative case score: I0, positive case score: 280. (E) PD-LI, membrane staining, mean $\mathrm{H}$-score: 4.8 , negative case score: 0 , positive case score: 50. (F) Cox-2; cytoplasmic staining, mean H-score: I8I, negative case score: 60, positive case score: 270. (G) SPARC in tumor tissue; cytoplasmic staining, mean $H$-score: 32, negative case score: 0 , positive case score: 90. (H) SPARC in stroma tissue; cytoplasmic staining, mean $H$-score: I22, negative case score: 10 , positive case score: 240.

Abbreviations: Cox-2, cyclooxygenase-2; ERCCI, excision repair cross-complementation group I; H-score, histologic score; PD-LI, programmed cell death-I ligand-I; RRMI, ribonucleotide reductase MI; SPARC, secreted protein acidic and rich in cysteine; TS, thymidylate synthase. 


\section{References}

1. Edelman MJ, Watson D, Wang X, et al. Eicosanoid modulation in advanced lung cancer: cyclooxygenase- 2 expression is a positive predictive factor for celecoxib + chemotherapy-Cancer and Leukemia Group B Trial 30203. J Clin Oncol. 2008;26(6):848-855.

2. Simsir A, Wei XJ, Yee H, Moreira A, Cangiarella J. Differential expression of cytokeratins 7 and 20 and thyroid transcription factor-1 in bronchioloalveolar carcinoma: an immunohistochemical study in fine-needle aspiration biopsy specimens. Am J Clin Pathol. 2004; 121(3):350-357.

3. He YW, Zhao ML, Yang XY, Zeng J, Deng QH, He JX. Prognostic value of ERCC1, RRM1, and TS proteins in patients with resected non-small cell lung cancer. Cancer Chemother Pharmacol. 2015; 75(4):861-867.
4. Sève P, Lai R, Ding K, et al. Class III beta-tubulin expression and benefit from adjuvant cisplatin/vinorelbine chemotherapy in operable non-small cell lung cancer: analysis of NCIC JBR.10. Clin Cancer Res. 2007;13(3): 994-999.

5. Hidalgo M, Plaza C, Musteanu M, et al. SPARC Expression Did Not Predict Efficacy of nab-Paclitaxel plus Gemcitabine or Gemcitabine Alone for Metastatic Pancreatic Cancer in an Exploratory Analysis of the Phase III MPACT Trial. Clin Cancer Res. 2015;21(21):4811-4818.

6. Borghaei H, Paz-Ares L, Horn L, et al. Nivolumab versus docetaxel in advanced nonsquamous non-small-cell lung cancer. $N$ Engl $J$ Med. 2015;373(17):1627-1639.

\section{Publish your work in this journal}

OncoTargets and Therapy is an international, peer-reviewed, open access journal focusing on the pathological basis of all cancers, potential targets for therapy and treatment protocols employed to improve the management of cancer patients. The journal also focuses on the impact of management programs and new therapeutic agents and protocols on

\section{Dovepress}

patient perspectives such as quality of life, adherence and satisfaction. The manuscript management system is completely online and includes a very quick and fair peer-review system, which is all easy to use. Visit http://www.dovepress.com/testimonials.php to read real quotes from published authors.

Submit your manuscript here: http://www.dovepress.com/oncotargets-and-therapy-journal 